\title{
LOS VERBOS INCOATIVOS DE LA CUARTA CLASE DE VERBOS DÉBILES EN GERMÁNICO Y SUS CORRESPONDENCIAS EN LAS DIFERENTES LENGUAS GERMÁNICAS ${ }^{1}$
}

Miguel Ayerbe Linares

Tanto en Germánico como en gótico había 4 clases de verbos débiles bien diferenciadas, de las cuales la cuarta se caracteriza — si bien no exclusivamente- por los llamados verbos incoativos. ${ }^{2}$ Por otro lado, y como muestran las correspondientes gramáticas, dicha clase de verbos ha desaparecido en las demás lenguas germánicas, ${ }^{3}$ exceptuando, claro está, algunos rastros que se observan en algunas de ellas como el islandés y el noruego, ante todo.

No obstante, los verbos incoativos ${ }^{4}$ como tales siguen siendo reconocibles y utilizados en las lenguas germánicas modernas, de modo que si la denominada cuarta clase de verbos débiles del Germánico desaparece, las lenguas germánicas se deben haber servido de otros recursos para poder expresar el modo de acción incoativo. Como dicen Prokosch (1981) y Egge (1886), la expresión de este modo de acción en los verbos débiles en Germánico se

\footnotetext{
${ }^{1}$ No quisiera comenzar la redacción de este trabajo sin dejar constancia de mi agradecimiento al Prof. Theo Vennemann de la Ludwig-Maximiliam-Universität de Munich, quien, no sólo me animó a realizarlo, sino que también me ofreció su apoyo y revisó muy atentamente su realización. La versión que presento ahora contiene algunas modificaciones procedentes, en parte, de las oportunas indicaciones que él mismo me dió. Al mismo tiempo se dirige mi agradecimiento al Dr. Rafael López-Campos de la Universidad de Sevilla por sus interesantes sugerencias para posteriores trabajos en este ámbito.

${ }^{2}$ Cfr. Braune, W./Ebbinghaus, E.A.: Gotische Grammatik. Tübingen 1981, pág. 125; Egge, A.E.: "Inchoative or $N$-Verbs in Gothic, etc". En: American Journal of Philology VII, 25 (1886), págs. 38-45; Streitberg, W.: Urgermanische Grammatik. Heidelberg 1943, pág. 314; Krahe, H.: Germanische Sprachwissenschaft II. Berlin 1969, pág. 119; Prokosch, E.: A Comparative Germanic Grammar. Philadelphia 1939, pág. 156; Ramat, P.: Einführung in das Germanische. Tübingen 1981, pág. 167.

${ }^{3}$ A este respecto hay diversidad de opiniones. Prokosch, por ejemplo, en la obra arriba citada afirma que en el antiguo nórdico existía una cuarta clase con verbos incoativos. De igual manera dice A. Noreen en su Altnordische Grammatik de 1904 que en antiguo nórdico hubo una cuarta clase de verbos débiles, en la que predominaban verbos transitivos o intransitivos que expresan estado.

${ }^{4}$ Antes de seguir quisiera puntulizar aquí que lo que en gótico se entiende como "verbos débiles de la cuarta clase" también abarcaba otros significados aparte del incoativo, como el medio-pasivo y el pasivo. Lo mismo hay que decir de las demás lenguas germánicas. En otras palabras, los verbos incoativos eran sólo una parte del grupo de verbos de la cuarta clase.
} 
llevaba a cabo mediante sufijos específicos, que tenían precisamente esa función. En el caso concreto de la cuarta clase, el sufijo que desempeñaba esta función era -nô. En gótico, este sufijo todavía se reconocía perfectamente, distiguiendo al mismo tiempo la clase verbal a la que pertenecía y desempeñando su función. Posteriormente, en las demás lenguas germánicas, sin embargo, ya se ha perdido total o en gran parte, desapareciendo con él la cuarta clase de verbos débiles.

Ante una situación como esta cabe entonces preguntarse, cómo ha desaparecido esta clase de verbos; hasta qué punto y en qué términos se puede hablar de desaparición; si tal desaparición ha afectado a todas las lenguas germánicas por igual, así como la pregunta que constituye la parte esencial de este trabajo: si desaparecen los medios de que se servía la expresión del modo de acción, este último no desaparece sino que sigue mostrando la necesidad de ser expresado, si bien ha de contar con ayuda de otros medios. La cuestión aquí sería entonces de qué medios se ha servido la expresión del modo de acción incoativo en las diferentes lenguas germánicas. Por tanto, con el presente estudio pretendo ofrecer una respuesta a todas estas cuestiones, analizando la situación no sólo en gótico y en alemán sino también en las demás lenguas germánicas, ya que todas ellas se ven afectadas por estos interrogantes (puesto que la diferenciación en cuatro clases de verbos débiles no era una propiedad o evolución particular reducida tan sólo al gótico o al alemán, sino del Germánico en general). Por otro lado, la razón por la que no me limito al caso del gótico y del alemán está en aprovechar los resultados de este trabajo para ofrecer en un único análisis una visión más amplia del fenómeno, ya que la mayor parte de la bibliografía — muy escasa, por cierto- que he leído al respecto se centra tan sólo en cuestiones cuyas conclusiones no dan respuesta a lo que ocurre con la expresión del modo de acción incoativo al desaparecer el sufijo -nô, lo cual, como he dicho un poco más arriba, será el objeto de análisis de este trabajo, sin que con ello quiera decir que dichas cuestiones - las tratadas por la bibliografía- a las que he podido acceder, sean dignas de menor consideración o que carezcan de valor.

Para el presente análisis he partido ante todo de gramáticas de las diferentes lenguas germánicas a lo largo de su desarrollo histórico, algunas citas de textos originales y de diccionarios etimológicos. En cuanto a la presentación, iré analizando lo que ocurre en cada lengua por separado, salvo las lenguas germánicas del norte de Europa que consideraré en parte en grupo en los estadios más antiguos, en parte por separado como lenguas modernas.

\section{A) EN GóTICO}

Según la gramática de gótico de Braune/Ebbinghaus (1981) los verbos débiles de la cuarta clase formados con el sufijo -nô expresaban por lo general el modo de acción incoativo. Streitberg (1943) afirma que estos verbos constituían un grupo semántico cerrado, concretamente, incoativo y pasivo. No obstante, hay que decir respecto a Braune/Ebbinghaus (1981) que la caracterización de estos verbos no resulta del todo precisa, ya que no sólo hay verbos que expresan un cambio de estado, sino también estado propia- 
mente dicho, como por ejemplo: af-lifnan ${ }^{5}$ 'permanecer', ga-bignan 'ser rico'. Por otro lado, se puede establecer una distinción entre verbos de la cuarta clase y sus, llamemoslo así, paralelos transitivos comprendidos en su mayoría en la primera clase de verbos débiles:

$$
\begin{aligned}
& \text { *gahailnan 'curarse' }{ }^{6} \text { vs. hailjan 'curar' } \\
& \text { *gawaknan 'despertarse' vs. *us-wakjan 'despertar' } \\
& \text { *auknan 'aumentar de tamaño' vs. biaukan 'engrandecer' } \\
& \text { *(af)blindnan 'volverse ciego' vs. *blindjan 'cegar a alguien' } \\
& \text { drôbnan 'volverse confuso' vs. drôbjan 'confundir' } \\
& \text { mikilnan 'aumentar de tamaño' vs. mikiljan 'enaltecer' } \\
& \text { *baursnan 'pasar a estar seco' vs. *paursjan 'tener sed' }
\end{aligned}
$$

A la vista de estos ejemplos se comprueba que, efectivamente, los verbos débiles seguían existiendo tal como se encontraban en el Germánico ${ }^{7}$, es decir, a cada clase verbal le correspondía la función de expresar un modo de acción concreto sirviéndose de un sufijo específico. A continuación un breve esquema ilustrativo sobre el que volveré un poco más adelante:

I.Clase con sufijo -ja-: causativo/factitivogot. dragkjan 'dar de beber'

II.Clase con sufijo -ô-: intensivo/iterativogot. karôn 'ocuparse de'

III.Clase con sufijo - $\hat{e}-$ : durativogot. liban 'vivir'

IV.Clase con sufijo -nô-: intransitivo/incoativogot. fullnan 'pasar a estar lleno'

\section{B) EN ALEMÁN}

En el ámbito de las lenguas germánicas occidentales hay que decir que la situación se presenta de una manera totalmente distinta, no sólo en comparación con el gótico, sino también con las lenguas germánicas del norte de Europa, como veremos más tarde. Si se

\footnotetext{
${ }^{5}$ La mayoría de los ejemplos que aquí se citan proceden de Jansen, O.: "Zur Funktion der gotischen -nan Verben". En: Gedenkschrift für Ingerid Dal VII (1988), págs. 54-62. Para las críticas a la gramática de gótico de Braune/Ebbinghaus remito al artículo de Jansen que acabo de citar. En este ar'ticulo, Jansen menciona a su vez la tesis de Hjalmar Annerholm titulada Studier över de inkoativa verben på -na(n). Lund 1956, sobre cuyos resultados se basan Braune/Ebbinghaus para su grmática.

${ }^{6} \mathrm{La}$ traducción al español de estos verbos no me parece muy acertada, ya que en español los verbos acabados en se resultan un tanto ambiguos al poder dar también a entender una acción en la que el propio sujeto es el agente de la acción mientras que "incoativo", en el sentido en que hablan los autores citados, expresan la entrada en una acción que implica a su vez un cambio de estado en el que el sujeto no participa activamente. En el caso de los ejemplos arriba citados, la traducción más segura sería 'pasar a estar curado' para * gahailnan y 'de estar dormido pasar a estar despierto' para *gawaknan.

${ }^{7}$ Para la situación en el Germánico, véase Ramat, P. op.cit., pág. 167. De él procede la clasificación expuesta a continuación. Para una exposición algo más extensa, véase también Tschirch, F.: Geschichte der deutschen Sprache I. Berlin 1983, págs. 72 y 73.
} 
observan las muestras existentes en alto alto alemán antiguo (en alemán Althochdeutsch) no será muy difícil comprobar que el número de ellas es muy reducido. Mientras la cifra de muestras de verbos incoativos acabados en -nan era muy amplio en gótico, antiguo nórdico y, en parte, también en inglés antiguo (Old English), en alto alto alemán antiguo, en cambio, apenas se pueden reconocer algunos verbos:
swînan 'volverse pequeño/pasar a tener menos tamaño'
wesanên 'echarse a perder/pasar a tener un mal estado'
storchanên 'pasar a estar en un estado seco'

Por otro lado, ya en alto alto alemán antiguo comienzan a aparecer nuevas formas, esta vez caracterizadas no por un sufijo sino más bien por un prefijo, concretamente $i r$-:

*iraltên 'envejecer'

*irbleihhên 'palidecer'

*irblinten 'volverse ciego/pasar a estar ciego'

*irbluhhen 'comenzar a arder'

De aquí se puede concluir que, en el caso de la lengua alemana, ha sido un prefijo el que ha asumido la función de expresar el modo de acción incoativo. No obstante, cuando se confrontan estos verbos con sus paralelos sin el prefijo ir-, (tal como hice de un modo parecido con el gótico) se observa que éstos también han debido expresar el modo de acción incoativo, además del durativo. Véase los siguientes pares:

*bleihhên junto a *irbleihhên, donde el primero significaba 'palidecer' o también 'estar pálido'.

$$
\begin{aligned}
& \text { *dorrên junto a *irdorrên 'pasar a estar rígido' } \\
& \text { *firnên junto a *irfirnên 'envejecer' } \\
& \text { fûlên junto a irfûlên 'pasar a un estado corrupto' }
\end{aligned}
$$

Una explicación a esta evolución en alemán sería la siguiente: como ya he dicho anteriormente, en Germánico se distinguían 4 clases de verbos débiles, cuyo rasgo distintivo se materializaba en un sufijo que indicaba el modo de acción verbal. Obsérvese una vez más el siguiente esquema:

I.Clase con sufijo -ja-: causativo/factitivogot. dragkjan 'dar de beber'

II.Clase con sufijo -ô-: intensivo/iterativogot. karôn 'ocuparse de'

III.Clase con sufijo - $\hat{e}$-: durativogot. liban 'vivir'

IV.Clase con sufijo -nô-: intransitivo/incoativogot. fullnan 'pasar a estar lleno'

Pues bien, según explica Erben (1993), estos sufijos habían perdido vigor y nitidez ya en alto alemán antiguo, lo que se puede demostrar fácilmente al observar que ya no hay 
cuatro clases de verbos débiles como en gótico, sino sólo tres, que, no obstante, aún se siguen diferenciando unas de otras:

$$
\begin{aligned}
& 1^{a} \text { clase con sufijo -e- }<\text { germ. -janzellen 'narrar' } \\
& 2^{a} \text { clase con sufijo-ô-salbôn 'ungir' } \\
& 3^{a} \text { clase con sufijo-ê-habên 'tener' }
\end{aligned}
$$

Como se puede observar en este reducido esquema, de las cuatro clases existentes en Germánico y gótico, sólo llegan al antiguo alemán las tres primeras. ¿Qué ha ocurrido entonces con la cuarta? Sonderegger (1987:217) explica la desaparición de esta clase de verbos argumentando que éstos han pasado a formar parte de la tercera en $-\hat{e}-{ }^{8}{ }^{8}$ Si seguimos adelante en la historia de la lengua alemana, nos encontramos con que en alto alemán medio (en alemán Mittelhochdeutsch), la diferencia entre sufijos ha desaparecido al mostrar todos los verbos débiles la misma terminación, a saber, -en, de modo que ya no es posible hacer una clasificación dentro de los verbos débiles. No obstante, esa pérdida de nitidez de que hablaba antes debió hacerse ya patente en antiguo alto alemán por las siguientes razones: en primer lugar, desaparece por completo la cuarta clase como grupo de verbos; en segundo lugar porque al pasarse a la tercera clase, ésta deja de ser ya tan específica como lo fuera antiormente y, por último, el gran parecido que se observa ya entre los sufijos temáticos de la primera y tercera clase, que ya sólo se distinguen en la cantidad vocálica.

Así pues, con la desaparición de la cuarta clase de verbos débiles como tal y la debilitación de los sufijos de las tres supervivientes — si se me permite decirlo así- queda se hace evidente que dichos sufijos dejan de estar en condiciones de seguir siendo el medio para expresar el modo de acción. Esta circunstancia tendrá entonces por consecuencia que habrá de ser otro el recurso que asuma esta función, ya que con la desaparición de un sufijo no desaparece la necesidad de expresar el modo verbal. La pregunta ahora sería, cuál es ese recurso del que se sirve el alemán, ya en sus estadios más antiguos, para expresar el modo de acción y, más concretamente, el modo incoativo.

Erben (1993) atribuye a los prefijos verbales un gran papel en este ámbito. Según él, los prefijos verbales fueron ganando terreno allí donde los sufijos iban cediendo, asumiendo funciones que hasta entonces no habían desempeñado, y entre las que se encontraba la expresion del modo de acción. ${ }^{9}$ Además, estos prefijos constituirán un sistema preciso de graduación y matización de las bases verbales.

\footnotetext{
${ }^{8}$ Compárese germ. *wakna (clase $4^{\mathrm{a}}$ ) con aniguo alemán wahhên (clase $3^{\mathrm{a}}$ ). Véase también los ejemplos en alto alemán antiguo ya citados más arriba.

${ }^{9}$ A raíz de lo que acabo de decir, quisiera apuntar marginalmente una hipótesis a demostrar que dejo abierta para
otro trabajo, porque se saldría del ámbito de este análisis. La hipótesis sería la siguiente: si en gótico no existían
aún los prefijos verbales inseparables -lo cual lleva a pensar que tampoco existieron en Germánico-, el hecho de
que en alto alemán antiguo aparecieran con gran frecuencia tendría su explicación precisamente en el aumento de
su importancia como portadores de funciones que antes no tenían y de las que habla Erben (1993), que les con-
vierte en elementos imprescindibles para la base verbal, convirtiéndose así en partes integrantes del verbo y, por
tanto, pasan a ser inseparables. De esta manera, se podría explicar el origen de los prefijos inseparables en alemán.
} 
En cuanto a los pares de verbos más arriba citados en los que tanto el verbo con el prefijo ir- como sus paralelos sin dicho prefijo *dorrên/irdorrên, firnên/*irfirnên pueden expresar el modo incoativo, el por qué de esta doble modalidad se explica de la siguiente forma. Si, como afirma Sonderegger (1987) y de hecho se observa fácilmente, los verbos germánicos de la cuarta clase pasan a formar parte de la tercera clase en alto alemán antiguo, éstos seguirían expresando el modo de acción incoativo hasta un punto en el que la distinción de los verbos debiles entre sí pierde todo su valor, asimilándose al mismo tiempo en la forma los verbos débiles de la tercera clase con los de la primera y, más tarde también con los de la segunda. Una de las consecuencias más directas de esta fusión de los sufijos temáticos de las distintas clases de verbos débiles sería que los verbos de la cuarta clase que en Germánico y gótico contaban con un paralelo transitivo-activo, pero que se diferenciaban precisamente en el sufijo que les asignaba un modo de acción específico, se convierten en unidades idénticas formalmente. En ese momento, el medio del que se servía la expresión del modo de acción en alemán desaparece y surge la necesidad de apoyarse en otro, y es ahí donde empieza a ganar relevancia el prefijo verbal que hoy conocemos como "inseparable". Nuevamente, son los verbos incoativos los que tienen que buscarse una nueva salida, tras pasar de una clase verbal propia a la tercera en alto alto alemán antiguo.

Esta evolución explicaría, por otro lado, la convivencia inicial que se daba entre los verbos simples y los derivados con el prefijo verbal inseparable a la hora de expresar el modo de acción incoativo, ${ }^{10}$ hasta que recursos como el prefijo ir- (alemán actual er-) se van imponiendo, permaneciendo entonces en algunos casos el verbo simple para el modo causativo o durativo. Esto se puede comprobar rápidamente al encontrar los dos verbos en el mismo texto: Er irbléchete, joh fárawun er wánta (I 4,25), ${ }^{11}$ nist ákar hiar in ríche, nub ér zi thiu nu bléiche (II 14,106), bigínnit thanne wéichen, ... (V 6,37), fon úngiloubon fésti irwéichent thio iro brústi (V 6,34). Así pues, la derivación con el prefijo ir- va imponiéndose como medio para expresar el modo de acción incoativo al mismo tiempo que un nuevo recurso hace aparición: la perífrasis con biginnan 'comenzar, originar(se) en el sentido de tener un comienzo', que también se utiliza para expresar el modo incoativo.

Más adelante, en alto alemán medio, se ve algo parecido en verbos como müeden y ermüeden, es decir, se siguen encontrando pares de verbos de los cuales uno es simple y el segundo derivado. No obstante, se observa ya con más intensidad lo que en alto alemán antiguo se comenzaba a desarrollar, aunque todavía no tan claramente. Ahora sólo verbos con el prefijo er- (<antiguo alemán ir-) expresan una acción en su modo incoativo, mientras que los verbos simples comienzan a aparecer cada vez con más frecuencia junto a verbos auxiliares, sobre todo beginnen, para expresar igualmente el modo incoativo. Por tanto, el prefijo er- ha asumido dicha función, si bien no pasa a ser la única, como se puede observar

\footnotetext{
${ }^{10}$ De hecho al consultar diccionarios de antiguo alemán se observa que los verbos simples expresan aún ambos significados, esto es, el causativo o durativo y el incoativo. Un ejemplo de ello es bleihhên, que puede aparecer como 'estar pálido' o 'pasar a estar pálido'.

${ }^{11}$ Citas de Otfrids Evangelienbuch, herausgegeben von Oskar Erdmann, 6. Auflage besorgt von Ludwig Wolff. Tübingen 1957.
} 
a lo largo de la historia de la lengua alemana, gótico, etc... Véase los ejemplos siguientes, también con otros verbos:

$$
\begin{aligned}
& \text { er begunde müeden } \\
& \text { daz die zwêne man muoden begunden } \\
& \text { do begunden sie bleichen von vorhten } \\
& \text { heizze wazzer âne viur beginnent kalten }
\end{aligned}
$$

En alemán moderno, junto al prefijo er-, hay otra posibilidad de formar una perífrasis con significado incoativo, que, en gran parte, se ha impuesto a la que en alto alemán medio fuera la más corriente (verbo + beginnen) consistente en el verbo werden + adjetivo: bleich werden(=erbleichen), blass werden (=erblassen), krank werden (=erkranken), kraftlos werden, etc... No obstante, y como ya dejé entrever antes, hay que decir que el prefijo verbal $e r$-, al modificar al verbo, tiene más funciones aparte de aquella que expresa el modo de acción incoativo. Siendo más exactos, la función de expresar el modo de acción incoativo es relativamente nueva, ya que este prefijo no surgió de la nada para expresar dicha función, sino que ya existía mucho antes desempeñando otras funciones, de manera que en un momento dado asumió esta nueva función, sumándose a las anteriores. Así, entre otras, erpuede modificar a un verbo para expresar un valor resultativo erschlagen, erbitten o local erheben, erbauen. Dichos verbos pueden ser además intransitivos o transitivos. Además, lo mismo hay que decir para el alto alemán antiguo y medio.

En cuanto a la pregunta de por qué el prefijo er- ha asumido la propiedad de expresar el modo incoativo no es fácil buscar una respuesta. Lo que sí está claro es que en gótico el prefijo $u z$ - (>alemán moderno er-) no tenía esta propiedad y, además, no era inseparable, lo cual refuerza, para empezar, los argumentos aportados hasta ahora. Tenía el significado 'de, desde, afuera'. Los diccionarios etimológicos del alemán (Kluge 1995; Pfeiffer 1993) añaden que el prefijo er- destaca hoy día por construir verbos incoativos por lo que, de nuevo, la conclusión es clara: si el prefijo er- antiguamente no tenía esta función, tuvo que asumirla entonces a lo largo de la evolución de la lengua alemana. Ahora bien, el por qué no lo dice nadie, al menos hasta donde he podido llegar hasta ahora. Pero, no obstante el interés por esta cuestión, habrá que reservarla para un trabajo posterior que se ocupe plenamente con ello.

\section{C) EN LAS LENGUAS GERMÁNICAS DEL NORTE DE EUROPA}

Las lenguas germánicas septentrionales son las que mejor han conservado los verbos incoativos tal como se hallaban en Germánico, al menos formalmente. Esto mismo es aplicable, no sólo a los estadios más antiguos de estas lenguas sino también a su estado actual.

No obstante, no se puede hablar hoy de una cuarta clase de verbos débiles como era el caso del Germánico y del gótico. En cuanto a los estadios anteriores, en cambio, se da una

\footnotetext{
${ }^{12}$ Estos ejemplos proceden de Lexer, M.: Mittelhochdeutsches Handwörterbuch I y II. Stuttgart 1992.
} 
diversidad de opiniones, ya que las gramáticas de antiguo nórdico consultadas no comparten las mismas posturas. Sólo Noreen (1970:349 s.) y Prokosch (1939:156) reconocen una cuarta clase de verbos débiles en antiguo nórdico, en la que — según Noreen- están incluidos verbos intransitivos como vaka 'estar despierto', brosa 'sonreir', hara 'vivir' y transitivos como vita 'observar'. Otros, en cambio, afirman que sólo hay tres clases, entre los que se encuentran Ranke/Hofmann (1988:68), o que la cuarta clase ha pasado a formar parte de la clase - $\hat{o}-$, postura que defiende Kuhn (1970).

Pero volviendo una vez más a la búsqueda de una razón por la que la cuarta clase de verbos débiles del Germánico - y que en gótico todavía se consera-, tampoco hay una respuesta. En este ámbito tan sólo Grimm (1837:23 ss.) describe el proceso por el que los verbos de la cuarta clase pasan a formar parte de la segunda, pero deja sin resolver la cuestión del por qué.

Pero, en fin, permanezcamos en el ámbito de este trabajo, intentando ofrecer un análisis de lo que ha ocurrido con la expresión del modo de acción incoativo a lo largo de la evolución de las lenguas germánicas y, más concretamente, en el de las lenguas germánicas del Norte. Como ya he dicho, la buena conservación, si bien tan sólo formal, de los verbos incoativos del Germánico se observa en la terminación -na, que ha perdurado hasta el día de hoy como se puede comprobar en el cuadro siguiente:

\begin{tabular}{|llllll|}
\hline anord. & mnoru. & msuec. & mdan. & misl. ${ }^{13}$ & alemán ${ }^{14}$ \\
\hline batna & batna & battna & - & batna & 'besser werden' \\
blana & blaana & blåna & blåna & blána & 'blau werden' \\
dofna & dovna & domna & dovne & dofna & 'schwach werden' \\
harðna & hardna & hårdna & - & harðna & 'hart werden' \\
hnigna & & - & - & hnigna & 'alt werden' \\
sjúkna & sjukna & sjukna & - & - & 'krank werden' \\
\hline
\end{tabular}

Ahora bien, estas lenguas, además de estos verbos acabados en -na han desarrollado una perífrasis de un modo muy parecido al alemán actual y que expresa el modo de acción incoativo. Se trata, pues, de la construcción Adjetivo + verbo auxiliar, que en alemán equivale a werden: bli en noruego y sueco moderno, blive en danés moderno y verða en islan-

\footnotetext{
${ }^{13}$ Las abreviaturas significan, por orden de izquierda a derecha: antiguo nórdico, noruego moderno, sueco moderno, danés moderno e islandés moderno.

${ }^{14} \mathrm{He}$ preferido introducir en el cuadro la traducción alemana en lugar de traducirlos directamente al castellano con el fin de ofrecer un contraste entre las mismas lenguas germánicas, a pesar de haber dejado para otro momento la situación que presenta la evolución del inglés. Las traducciones, por orden de arriba a abajo: 'mejorar', 'volverse azul', 'volverse débil', 'volverse duro o rígido', 'envejecer', 'pasar a estar enfermo'.
} 
dés moderno. Estas perífrasis se pueden utilizar en dichas lenguas en lugar de los verbos en -na. A continuación, algunos ejemplos:

\section{En noruego}

blekne / bli blek 'volverse pálido'

kjølne / bli kald 'pasar a estar frío'

størkne bli hard 'pasar a estar rígido'

En danés

$k \phi l n e$ / blive kold 'pasar a estar frío'

stivne / blive stiv 'pasar a estar rígido'

En sueco

stelne / bli stel 'pasar a estar rígido'

sjukna / bli sjuk 'pasar a estar enfermo'

En islandés

dofna / verða dofinn 'volverse débil'

roðna / verða rauður 'volverse rojo'

uldna / verða úldinn 'echarse a perder'

vakna / verða vakandi 'pasar a estar despierto'

\section{D) EN INGLÉS}

En inglés, la situación vuelve a ser distinta, sin embargo, se parece mucho a lo ocurrido en alemán. Para empezar, si se observan los estadios más antiguos de la lengua inglesa se llega a la conclusión de que tampoco poșeía una cuarta clase de verbos débiles que reuniera los verbos incoativos tal como el Germánico y el gótico mostraban. En cuanto a la pregunta sobre lo ocurrido con dicha clase verbal, apenas se ha dicho algo: sólo Hogg (1992:157) afirma que esta clase ha desaparecido totalmente, pero no hay nada que se dedique a explicar el por qué.

No obstante, en inglés antiguo se pueden reconocer aún algunos verbos que, sin pertenecer a ninguna clase cuarta de verbos débiles, si conserva, en cambio la forma de dichos verbos, tal como se obsevara en aniguo nórdico:

brosnian 'pasar a descomposición'

molsnian 'pudrirse'

pwînan 'pasar a ser más pequeño'

woenan 'pasar a estar despierto'

weornian 'pasar a estar débil' 
En inglés medio se pueden reconocer aún algunos como brosnien y bliknen 'volverse pálido'.

Por otra parte, y dado que en inglés antiguo había prefijos verbales, cabe suponer que el prefijo equivalente a $i r$ - en alto alemán antiguo, es decir, $\hat{a}$-, y siguiendo el proceso que ha tenido lugar con dicho prefijo en alemán, hubiera podido ocurrir que el prefijo $\hat{a}$ - hubiera adoptado la función de expresar el modo incoativo al igual que hiciera su correspondiente en alemán. Así parece haber ocurrido, desde luego, si se observa la siguiente lista de verbos en inglés antiguo:

$$
\begin{aligned}
& \text { âbit(e)rian 'to turn bitter' } \\
& \text { ablâcian 'to turn pale' } \\
& \text { abblindian '16 'to become pale' } \\
& \text { âcealdian 'to become cold' } \\
& \text { âdeorcian 'to become dull' }
\end{aligned}
$$

No obstante, resulta muy sospechoso que estos verbos signifiquen lo mismo que sus correspondientes "simples", es decir, sin el prefijo $\hat{a}-$, como biterian, blâcian, cealdian, deorcian. ${ }^{17} \mathrm{Si}$ examinamos la situación en inglés medio, encontraremos exactamente lo mismo:

$$
\begin{aligned}
& \text { ablîkenblîken 'to grow pale' } \\
& \text { acaldencalden 'to grow cold' } \\
& \text { adêavendêaven 'to grow deaf' }
\end{aligned}
$$

Al observar estas breves relaciones de verbos uno se podría preguntar entonces cómo es posible que existieran ambos tipos de verbos para expresar lo mismo. La respuesta a este interrogante la ofrecen Kurath/Kuhn (1956:4), quienes dicen que ya en inglés medio (Middle English), el prefijo â- no constituía ninguna diferencia frente al verbo simple. La razón es muy sencilla: a pesar de lo que las sospechas, que antes he presentado, llevan a pensar, el prefijo $\hat{a}$-, sin embargo, no modificaba ni en inglés antiguo ni medio a la base verbal de modo que diera lugar a la expresión del modo de acción incoativo. Es más, las gramáticas de inglés antiguo, así como manuales de historia de la lengua inglesa no atribuyen dicho papel a este prefijo.

Otra razón es la siguiente: el prefijo â- tenía en inglés antiguo, al igual que sus correspondientes en gótico (us-), en alto alemán antiguo (ir-), antiguo nórdico ( $(\hat{a}-)$, el significado "de, hacia fuera" ( en alemán "aus, von"), pero no el de servir de soporte para expresar el modo incoativo. En alemán, en cambio, asumió este prefijo, es decir ir-, esta función junto

\footnotetext{
${ }^{15}$ El por qué de ofrecer las traducciones de estos verbos en inglés tiene, naturalmente, su explicación, la cual daré más adelante, con el fin de seguir un orden en esta exposición.

${ }^{16}$ Frente a âblindan 'to make blind'.

${ }^{17}$ Todos los ejemplos provienen de Hall (1931).
} 
a las otras que ya tenía anteriormente y que compartía con las demás lenguas germánicas; pero este fue el caso sólo del alemán y no en inglés, donde $\hat{a}$-, sin embargo, podía dar al verbo una connotación de intensidad (Hiltunen 1983) pero no modificaba esencialmente el significado del verbo.

Por otro lado, a la hora de buscar una explicación a la pregunta de por qué los prefijos verbales no asumieron la función de expresar el modo incoativo, ninguno de los autores consultados se ha ocupado de ello. Todo lo más se reduce al tratamiento de los prefijos en inglés antiguo así como su desaparición. ${ }^{18}$ No obstante, al leer dicha bibliografía, así como de su visión global, se puede extraer fácilmente una explicación al comprobar que dichos prefijos estaban ya perdiendo uso y significado hasta que, llegado un momento, desaparecieron en inglés medio temprano, siendo sustituídos por otras formas cuyo valor semántico era más preciso (De la Cruz 1975, Hiltunen 1983). Dicho en otras palabras y aplicado al tema que nos ocupa aquí, cuando en inglés antiguo se perdió la diferenciación de los verbos débiles entre sí, ello afectó también a los verbos incoativos de la cuarta clase. Por tanto, había que buscar un medio de seguir expresando el modo incoativo. Entre las posibles soluciones se encontraría —al igual que en alemán - el recurso al prefijo $\hat{a}^{-}$, pero los prefijos verbales se encontraban ya en tal fase de debilitación que ya no estaban condiciones de asumir tal función De este modo se explica por qué no llegaron a asumir la misma función que se observa en alemán, es decir, la de la expresión del modo incoativo. ${ }^{19}$

Así pues, no fue un prefijo verbal el que asumió la función de ser el medio para expresar una acción verbal en modo incoativo. ¿De qué recurso se ha servido entonces la lengua inglesa para expresar el modo incoativo? La respuesta a esta pregunta guarda precisamente una muy estrecha relación con el hecho de haber ofrecido traducciones al inglés moderno de los verbos en inglés antiguo y medio que he presentado más arriba, en lugar de hacerlo directamente al castellano. Con ello quería ofrecer de una manera gráfica y directa cómo se ha desarrollado todo este proceso en inglés hasta llegar a nuestros días. En definitiva, y como se habrá podido ya comprobar, el inglés se ha servido de construcciones perifrásticas consistentes en un verbo auxiliar + un adjetivo, que no son ni mucho menos modernas, sino que más bien se utilizaban ya en inglés medio, como se puede ver en casos como his blod bigan to colde o hire heorte bigan to chelde ${ }^{20}$ La productividad de este recurso a las perífrasis queda, además demostrado por el hecho de disponer de diferentes verbos auxiliares como become, grow, turn, y con menos frecuencia, fall, get, go.

\footnotetext{
${ }^{18}$ Véase, entre otros, Hiltunen, R.: "The Decline of the Prefixes and the Beginnings of the English Phrasal Verb", 1983.

${ }^{19}$ Para seguir más detenidamente este proceso, así como las formas ante las cuales claudicaron los prefijos verbales, tal como se conocen hoy día en alemán, vésae el artículo de Juan M. de la Cruz: "Old English Pure Prefixes: Structure and Function", 1975.

${ }^{20}$ Ejemplos tomados de Clark Hall, J.R.: A Concise Anglo-Saxon Dictionary. Cambridge 1931.
} 


\section{E) CONCLUSIONES}

Tras contemplar en su conjunto lo que ha ocurrido con la expresión del modo de acción incoativo desde el Germánico hasta las modernas lenguas germánicas, la primera conclusión a la que se llega es, sin duda, que no nos encontramos ante un modelo de evolución uniforme y sistemático, sino que prácticamente cada lengua ha seguido un proceso distinto de desarrollo en este ámbito, exceptuando, claro está, determinadas similitudes: Por otro lado, se trata de un tema para el cual apenas existe bibliografía que se haya ocupado del caso y, cuando la hay, ésta se limita tan sólo a la consideración de aspectos fonológicos y morfológicos que afectan tanto a la estructura de los verbos débiles germánicos como a los denominados prefijos verbales. Pero hay que decir que casi ninguno ${ }^{21}$ se ha dedicado a analizar detenidamente lo que ocurre con la expresión del modo de acción incoativo al desapararecer la cuarta clase de verbos débiles, ni por qué tuvo que ser precisamente la cuarta clase la que tendría que desaparacer en primer lugar, ni tan siquiera por qué motivos desaparece.

Pero volviendo una vez más al objeto de este trabajo, es decir, la observación de los recursos de los que se sirven las diferentes lenguas germánicas para expresar el modo incoativo tras desaparecer la cuarta clase de verbos débiles, la única excepción a esta diversidad de desarrollos la constituye el gótico, lengua que conserva la cuarta clase de verbos tal como se constituían en germánico. En cuanto a las demás lenguas germánicas, la cuarta clase de verbos débiles como tal ha desaparecido por completo. No obstante, las lenguas germánicas septentrionales, si bien desde los estadios más antiguos ya habían perdido la cuarta clase, mantienen en cambio desde el punto de vista formal la construcción de los verbos incoativos mediante el sufijo -na, sobre todo, cuando más al norte se mira, ya que dichos verbos predominan claramente en islandés moderno. En este sentido, se puede decir que, dentro de las lenguas germánicas, las del norte de Europa son las que más conexión guardan con lo que se encontraba en el Germánico. Por otro lado, estas lenguas han desarrollado junto a estos verbos terminados en -na construcciones perifrásticas, cuyos verbos auxiliares coinciden, desde el punto de vista semántico, con el alemán werden. Así pues, de una parte, se han mantenido en formas sintéticas (verbos acabados en -na), de otra, han desarrollado formas analíticas.

El alemán también ha buscado una solución sintética, sólo que ahora la función de expresar el modo de acción incoativo pasa de un sufijo a un prefijo (er-), como portador. Pero dicho prefijo, no se crea para dicho fin, sino que ya existía antes con otras funciones. No obstante, también recurre a formas analíticas mediante la construcción perifrástica werden + adjetivo.

Finalmente, el inglés es la lengua que más se diferencia del resto, en lo que respecta a la evolución, ya que abandona las formas sintéticas para terminar utilizando formas analíticas. Una prueba de ello es la variedad de verbos auxiliares de que dispone para este fin. No

${ }^{21}$ Digo "casi ninguno", no porque haya habido alguien que se haya ocupado de ello ofreciendo una respuesta, sino más bien porque al menos plantea el problema pero, sin embargo, no entra en él para resolverlo. 
obstante, hay que decir que no todo el proceso de evolución ha sido totalmente distinto. A través de los éjemplos que he citado en el apartado correspondiente al inglés, se puede comprobar que en su estadio más antiguo contaba con un corpus, si bien ya muy reducido, de verbos que todavía se formaban como aquellos pertenecientes a la cuarta clase del Germánico. Por otro lado, ya en el inglés medio, cuando se utilizan las formas analíticas, éstas son muy parecidas a las que se usan en alto alemán medio, por poner un ejemplo. Sólo más tarde, el inglés se ha decidido por el recurso a formas analíticas cuyos verbos auxiliares, además, son distintos de los que utiliza el alemán y las lenguas germánicas septentrionales, ante todo el islandés (verða).

Antes de terminar, quisiera recoger algunos interrogantes que he mencionado de algún modo más arriba y proponerlos como cuestiones a tratar en otros estudios que complementen al presente, ya que durante el proceso de realización de este trabajo se comprueba que queda aún mucho por decir sobre el tema aquí plantedado. Algunos de esos interrogantes son la explicación al por qué de la desaparición precisamente de la cuarta clase de los verbos débiles mientras se mantienen las tres restantes; por qué, aunque sólo sea en el plano formal, han sido las lenguas germánicas del norte de Europa las que mejor han conservado dichos verbos en -na y, al mismo tiempo, si tiene alguna explicación que el grado de conservación sea mejor a medida que se avanza hacia el norte. Otra cuestión a plantear sería, por qué el alemán se inclina especialmente por los prefijos verbales. Como éstas, pueden surgir muchas otras preguntas, cuyo análisis tienen mucho que aportar al presente trabajo.

\section{BIBLIOGRAFÍA:}

\section{Diccionarios y fuentes:}

Andresen, J. [et al.], Langenscheidts Taschenwörterbuch Dänisch, (Berlin, 1995).

Bork, E., Gyldendal Tysk-Dansk Ordbog, 12. udgave, 5. oplag (Copenhagen, 1991).

Bußmann, H., Routledge Dictionary of Language and Linguistics, ed. G.P. Trauth and K. Kazzazi, (London, 1996).

Clark Hall, J.R., A Concise Anglo-Saxon Dictionary, third edition (Cambridge, 1931).

Craigie, W.A., An Icelandic-English Dictionary, second edition (Oxford, 1957).

De Vries, J., Altnordisches Etymologisches Wörterbuch, (Leiden, 1957).

DUDEN. Das Große Wörterbuch der deutschen Sprache, 8 Bände, 2. Auflage (1993/5).

DUDEN. Das Herkunftswörterbuch, 2. Auflage (Mannheim, 1989).

DUDEN. Die Grammatik, 5. Auflage (Mannheim, 1995).

Etymologisches Wörterbuch des Deutschen, hrsg. von W. Pfeiffer, 2 Bände, 2. Auflage (Berlin, 1993).

Feist, S., Vergleichendes Wörterbuch der gotischen Sprache, (Leiden, 1939). 
Götz, G./Haensch, G./Wellmann, H. ed., Langenscheidts Großwörterbuch. Deutsch als Fremdsprache, (Berlin, 1998).

Grimm, J. u. W., Deutsches Wörterbuch, 33 Bände (Leipzig, 1854-1971).

Gyldendals Handwörterbuch Norwegisch, (Berlin, 1995).

Íslenzk orðabók handa skólum og almenningi, riststjóri Árni Böðvarsson (Reykjavík, 1963).

Kluge, F., Etymologisches Wörterbuch der deutschen Sprache, 23. Auflage (Berlin, 1995).

Köbler, G., Altenglisch-Neuhochdeutsches und Neuhochdeutsch-Altenglisches Wörterbuch, (Gießen, 1985).

—,Althochdeutsch-Neuhochdeutsch-Lateinisches.Wörterbuch, 2 Bände, 3. Auflage (Gießen, 1991/2).

-,Altnordisch-Neuhochdeutsch und Neuhochdeutsch-Altnordisches Wörterbuch, (Gießen, 1986).

—,Gotisches Wörterbuch, (Leiden, 1989).

Kurath, H./Kuhn, S.M. [u.a.], Middle English Dictionary, 19 Bände (London, 1956-1994).

Lehmann, W.P., A Gothic Etymological Dictionary, (Leiden, 1986).

Lexer, M., Mittelhochdeutsches Handwörterbuch, 3 Bände (Stuttgart, 1992).

Onions, C.T., The Oxford Dictionary of English Etymology, (Oxford, 1966).

Otfrids Evangelienbuch, hrsg. von O. Erdmann, 3. Auflage von L. Wolf (Tübingen, 1957).

Prisma Handwörterbuch Schwedisch-Deutsch/Deutsch-Schwedisch, 2 Bände, (Berlin, 1984/9).

Schützeichel, R., Althochdeutsches Wörterbuch, 4. Auflage (Tübingen, 1989).

Stratmann, F.H., A Middle-English Dictionary, (Oxford, 1891).

\section{Bibliografía secundaria:}

Annerholm, H., Studier över de inkoativa verben på na(n) i gotiskan och de nordiska fornspråken, Stockholm studies in scandinavian philology 14, (Lund 1956).

Behaghel, O., Deutsche Syntax, 4 Bände, (Heidelberg, 1924).

Braune, W./Ebbinghaus, E.A., Gotische Grammatik, 19. Auflage (Tübingen, 1981).

De la Cruz, J.M., “Old English Pure Prefixes: Structure and Function”, Linguistics, 145 (1975), 47-81.

DUDEN. Grammatik der deutschen Gegenwartssprache, 5. Auflage (Mannheim, 1995), IV. 
Egge, A.E., "Inchoative or N-Verbs in Gothic, etc", The American Journal of Philology, 7 (1886), S. 38-45.

Erben, J., Einführung in die deutsche Wortbildungslehre, 3. Auflage (Berlin, 1993).

Grimm, J., Deutsche Grammatik, 4 Bände, (Göttingen, 1837)

Gruber, H., Das adverbale uz-Präfix im Gotischen und Althochdeutschen, Jenaer Germanistische Forschungen, 13 (Jena, 1930).

Heusler, A., Altisländisches Elementarbuch, (Heidelberg, 1913)

Hiltunen, R., The decline of the prefixes and the beginnings of the English Phrasal verb, Annales Universitatis Turkuensis, Serie B, Tom. 160 (Turku, 1983).

Hogg, R.M. (ed.), The Cambridge History of the English Language, 5 Bände (Cambridge, 1992).

Jansen, O., "Zur Funktion der gotischen -nan- Verben", Gedenkschrift für Ingerid Dal, 7 (1988), 54-62

Kluge, F., Urgermanisch, 3. Auflage (Strassburg, 1913).

Krahe, H., Germanische Sprachwissenschaft, 3 Bände, 7. Auflage (Berlin, 1969).

Kuhn, H., "Altnordisch", in Kurzer Grundriß der germanischen Philologie bis 1500, 2 Bände, ed. L.E. Schmitt (Berlin 1970), S. 123-143.

Noreen, A., Altnordische Grammatik, 2 Bände, (Tübingen, 1970).

Prokosch, E., Comparative Germanic Grammar, (Philadelphia, 1939).

Ramat, P., Einführung in das Germanische, Linguistische Arbeiten 95, (Tübingen, 1981).

Ranke, F./Hofmann, D., Altnordisches Elementarbuch, (Berlin, 1988).

Seip, D. A., Norwegische Sprachgeschichte, (Berlin, 1971).

Sievers, E., Altenglische Grammatik nach der angelsächsischen Grammatik, (Halle, 1942).

Sonderegger, S., Althochdeutsche Sprache und Literatur, 2. Auflage (Berlin, 1987).

Streitberg, W., Urgermanische Grammatik, (Heidelberg, 1943).

Tschirch, F., Geschichte der deutschen Sprache, 2 Bände, 3. Auflage (Berlin, 1983).

Wessén, E., Schwedische Sprachgeschichte, 3 Bände, (Berlin, 1970).

Wright, J., Old English Grammar, (Oxford, 1982). 
